\title{
Product assortment and customer mobility
}

\author{
Michele Coscia ${ }^{1 *}$, Diego Pennacchioli ${ }^{2,3}$ and Fosca Giannotti ${ }^{2}$
}

"Correspondence:

michele_coscia@hks.harvard.edu

${ }^{1} \mathrm{CID}$, Harvard University, 79 JFK St, Cambridge, USA

Full list of author information is available at the end of the article

\begin{abstract}
Customers mobility is dependent on the sophistication of their needs: sophisticated customers need to travel more to fulfill their needs. In this paper, we provide more detailed evidence of this phenomenon, providing an empirical validation of the Central Place Theory. For each customer, we detect what is her favorite shop, where she purchases most products. We can study the relationship between the favorite shop and the closest one, by recording the influence of the shop's size and the customer's sophistication in the discordance cases, i.e. the cases in which the favorite shop is not the closest one. We show that larger shops are able to retain most of their closest customers and they are able to catch large portions of customers from smaller shops around them. We connect this observation with the shop's larger sophistication, and not with its other characteristics, as the phenomenon is especially noticeable when customers want to satisfy their sophisticated needs. This is a confirmation of the recent extensions of the Central Place Theory, where the original assumptions of homogeneity in customer purchase power and needs are challenged. Different types of shops have also different survival logics. The largest shops get closed if they are unable to catch customers from the smaller shops, while medium size shops get closed if they cannot retain their closest customers. All analysis are performed on a large real-world dataset recording all purchases from millions of customers across the west coast of Italy.
\end{abstract}

Keywords: marketing; complex systems; mobility

\section{Introduction}

Customers in the retail market are rational entities, driven by more complex rules than the ones usually considered by classical economic theory. For instance, they are creatures of habit, making their movements rather predictable on the long run, as they will tend to visit the same shops [1]. More importantly, customers are characterized by different levels of sophistication. Some customers purchase only basic products, while others have more sophisticated needs. The amount of sophistication that a customer requires and a shop can satisfy have been shown to be good predictors of the customer's probability of visiting a particular shop [2]. This predictive power is stronger than traditional economic variables, such as the product's price. On top of this result, we discovered that the retail market behaves like a complex system driven by the sophistication needs of each customer [3].

In this paper, we expand this related literature. Specifically, we connect it to the Central Place Theory (CPT). CPT states that human settlements emerge as a hierarchical system

(c) 2015 Coscia et al. This article is distributed under the terms of the Creative Commons Attribution 4.0 International License (http://creativecommons.org/licenses/by/4.0/), which permits unrestricted use, distribution, and reproduction in any medium, provided you give appropriate credit to the original author(s) and the source, provide a link to the Creative Commons license, and indicate if changes were made. 
of centers of various sizes. The few larger centers provide a higher order of goods and services, which have a larger range, which in turn causes people to be willing to travel longer distances to acquire them [4]. In this paper, we provide empirical evidences of this very decision-making process happening among customers in a retail scenario: customers decide to ignore the closest shop to their location if it is unable to satisfy their complex needs. The shop type has a great influence over customer movements. Larger shops, that can provide a more differentiated offer of products, attract more customers, whether they are the closest or not.

According to the classical theory, only the product type matters. In fact, we observe that customers are more likely to go to a non-closest shop to buy more expensive products, products they need in lower quantity and more complex products. The strength of the effect is larger for complex products, then for low quantity products and finally for prices, that is the weakest variable. When customers go more frequently to a shop that is not their closest, on average their behavior differs only to a limited extend. However, focusing on the set of costumers who are modifying their behavior, the effect is clear. Further, this paper sustains more modern formulations of CPT [5], developed to address some of the oversimplifications of the original theory [6]. The observed effects are stronger for more sophisticated customers, challenging the assumption of homogeneity in consumers, who are assumed to have the same income level and the same shopping behavior.

To show these results we divide shops in different types. Shops can be either 'Iper, 'Super' or 'Gestin' depending on their size and product variety offer. For each pair customer-shop, we can classify the shop in favorite if it is the shop where the customer purchases most of her products; and closest, if it is the shop that is most easily reachable starting from the customer's home location. We can also classify products in high/low expenditure products, products that are needed often/rarely and products that satisfy sophisticated and non-sophisticated needs.

We define retention rate of a shop as the share of the customers that have that shop as closest and favorite. On the other hand, the catch rate of a shop is the share of customers that have that shop as favorite even if it is not their closest one. The retention and catch rates are calculated for every shop and product type, showing the diverging patterns we described before.

With the retention and catch rates, we can uncover useful patterns related to the odds of a shops to be closed down. The size of the shop interacts with the decision of closing it or keeping it open. From our data, we see that larger shops are expected to have high catching rates. If large shops are unable to catch customers from the smaller shops, then they get closed down. On the other hand, medium size shops are evaluated according to their ability of preserving their nearby customers. These medium shops get closed if they cannot retain their closest customers. Smaller shops appear to follow neither logic.

All the results and analyses presented in this paper are based on a large dataset recording real world transactions. The dataset originates from one of the leading retail market chains in Italy. The data includes information about 125 shops and more than half a million customers. The observations have been recorded for a time spanning six years. The data includes the addresses of both the shops and the customer's homes. We calculated the routes from each customer home to the nearby shops using the APIs of Google Maps. 


\section{The data}

Our analysis is based on real world data about customer behavior. The dataset we used is the retail market data of one of the largest Italian retail distribution companies. The data source of this work is the same used in our previous works [2,3]. We refer to these papers for a more detailed description of the general dataset, its conceptual schema and the discussion of representativeness of the data. Here, we only describe the data we selected for the analysis of this paper.

Our data covers the time span going from January 1st, 2007 to February 28th, 2013. The data has been collected from 125 shops, that cover the whole west coast of Italy. Shops are organized by the company in different classes. In increasing order of size we have 'Gestin', 'Super' and 'Iper.' 'Gestin' are usually low area shops, occupying the ground floor of a building, usually in the city center and in smaller towns and villages. 'Super' are larger, usually occupying their own building and built into larger cities just outside the city center. 'Iper' are usually an Italian equivalent of US malls. The data includes two extra metadata about the shop: its address; and its dates of operation, including the opening date and, if the shop has been closed, its closing date.

All transactions recorded by any shop active during this period of time is included in our data. We can associate an individual customers to each item she purchased and the time of her purchase if she used her membership card. The overall number of recognizable customers is $1,066,020$. When a customer obtains her membership card, she has to provide some information to the retail company, including her home address. We use this information to locate the customer on the territory. This allows us to clean the data. Many customers have moved from a different area of Italy, or they are tourists living far away from the west coast of Italy and they have a membership card only for the few weeks in which they visit the area. In either case, these population groups would introduce noise in the analysis. We drop all customers whose closest shop is 25 kilometers away or farther (calculated using straight line distance). We end up with 544,225 customers.

Later in the paper we need to estimate the price, quantity of need and sophistication of products. For efficiency purposes, we do not count each different item as a separate product, because this type of distinction, e.g. different sizes of bottles containing the same liquid, is not of interest in our study. We use the marketing classification of the retail company to aggregate equivalent classes of products. We also exclude from the analysis all segments that are either too frequent (e.g. the shopping bag) or meaningless for the purchasing analysis (e.g. discount vouchers, errors, segments never sold, etc.). Note that, in the rest of the paper, when we use the term 'product' we refer to this aggregated marketing category (i.e. 'milk' is a product), while the term 'item' is used when we refer to a specific instantiation of the product (i.e. a specific physical bottle of milk).

\section{Methods}

\subsection{Definitions}

In the paper, we are investigating the dynamics of customer mobility. In particular, we are interested in why customers decide to visit a particular shop more frequently than others, making it their favorite. Is it because the shop was simply the most reachable for them or are there other reasons? To answer this question, we need to define two main concepts: the concept of 'favorite' shop and the concept of 'closest' shop. We start by defining favorite as follows: 
Definition 1 (Favorite) Given a shop and a customer, the shop is defined as the customer's favorite iff the person bought more than $75 \%$ of her items there.

This definition implies that a customer can have only one favorite shop, but she is allowed to have none. As for closest shops, there are two ways to define spatial proximity. One involves considering the route from the customer's location to the shop location, the other considers how much time it takes to actually travel along this route. Our definitions of closest shops are then the following:

Definition 2 (Closest (Space)) Given a shop and a customer, the shop is defined as the customer's closest iff the there is no other shop that can be reached from the customer's home location using a shorter road route.

Definition 3 (Closest (Time)) Given a shop and a customer, the shop is defined as the customer's closest iff the there is no other shop that can be reached from the customer's home location in a shorter time.

In both cases, ties are allowed, i.e. customers are allowed to have more than one 'closest' shop. The spatial granularity of our data is 100 meters, while the temporal granularity of our data is the minute. Therefore, two shops can both be spatially close if they are within our 100 meters resolution, and they can be both temporally close if it takes the same number of minutes to reach them from the customer's location. Note that a shop that is the closest spatially might not be closest temporally. We decided to use both a spatial and a temporal definition of distance in this paper to ensure the robustness of our discussion. If the two distance measures would show different patterns then our results would have been non existent.

\subsection{Customer-shop connections}

As introduced before, we need to connect each customer with its favorite and closest shop. To detect the favorite shop of a customer is a trivial task. For each customer we have a trace of all the items she purchased, in which shop $s$ she purchased them and when. We simply aggregate this information by counting how many single items she purchased in each shop she visited. If $I_{c, s}$ is the set of all items $i$ purchased by customer $c$ in shop $s$, then the fidelity measure $\phi(c, s)$ is defined as:

$$
\phi(c, s)=\frac{\left|I_{c, s}\right|}{\left|I_{c,}\right|}
$$

where $I_{c, r}=\bigcup_{\forall s \in S} I_{c, s}$. If $\exists s$ for which $\phi(c, s)>0.75$ then customer $c$ has $s$ as her favorite shop.

To detect closest shops is less trivial. We cannot use a straight line distance as done in [2], because it is unrealistic and it will not represent well the actual distance from the customer to the shop. Moreover, the straight line distance does not help us in evaluating our temporal definition of distance. Since we have the addresses of both the shop and the customer, we systematically query the Google Directions APIs of Google Maps. ${ }^{\text {a }}$ Querying all possible $544,225 \times 125$ combinations is infeasible, so we decided to submit a query for a customer-shop pair only if their straight line distance is 25 kilometers or less. With this 
filter, each customer has only up to 5-6 alternative shops, with most customers having 3 shops or less.

The APIs return us the shortest path taking into account the road graph, which is a reasonable estimate of the route the customers will actually use to reach the shop. ${ }^{\mathrm{b}}$ For this route, the APIs report both the total distance in meters and the estimate number of seconds the trip would take. We round up this data into a resolution of 100 meters and of a minute to avoid taking into consideration meaningless distinctions between routes that have a time difference in the order of seconds.

\subsection{Product classifications}

For our analysis, we need to classify products according to different criteria, to test the effect of different product characteristics on customer's mobility. We use three different criteria: price, quantity of purchase and sophistication.

\subsubsection{Price}

A product is part of the high price class if its unit price is above the median, otherwise it is part of the low price class. We know how much customers pay for each item. A product $p$ is a set of items $i$. Each item has a price $\pi_{i}$. The product unit price $\pi_{p}$ is calculated as follows:

$$
\pi_{p}=\frac{\sum_{\forall i \in p} \pi_{i}}{|p|}
$$

that is the average item price of all items in $p$. Considering all observed $p$ sold at all the observed shops, we have a distribution of $\pi_{p}$. We calculate $\bar{\pi}$ as the median of this distribution. Then, $\Pi_{p}$ indicates $p$ 's price class as follows:

$$
\Pi_{p}= \begin{cases}1, & \text { if } \pi_{p}>\bar{\pi} \\ 0, & \text { otherwise }\end{cases}
$$

\subsubsection{Quantity}

A product is part of the high quantity class if its number of units sold is above the median, otherwise it is part of the low quantity class. This classification step is specular to the one described above for the price. The difference is that all items weigh the same in the calculation (namely they weigh 1), instead of having their own $\pi_{i}$ weight. So each product quantity $\gamma_{p}$ is simply $|p|, \bar{\gamma}$ is the median of the distribution, and $p$ 's quantity class $Q_{p}$ is calculated as:

$$
Q_{p}= \begin{cases}1, & \text { if } \gamma_{p}>\bar{\gamma} \\ 0, & \text { otherwise }\end{cases}
$$

\subsubsection{Sophistication}

A product is part of the high sophistication class if it is bought only by customers buying all kinds of products. If a product is bought by everyone, even those people buying only a handful of products, then it is part of the low sophistication class. We already introduced the product sophistication measure in previous works [3], that is an adaptation of the 
concept of product complexity in international trade data [7], which can be defined in different ways [8]. We refer to these papers for a deeper understanding of the sophistication measure.

As in the previous cases, each product $p$ is associated with a sophistication value $\sigma_{p}$, with $\bar{\sigma}$ we refer to the median of this distribution, and $p$ 's sophistication class $S_{p}$ is calculated as:

$$
S_{p}= \begin{cases}1, & \text { if } \sigma_{p}>\bar{\sigma} \\ 0, & \text { otherwise }\end{cases}
$$

\subsection{Retention and catch rates}

The two final central concepts used in this paper are the retention and the catch rates. Informally, the retention rate is the share of customers who have their closest shop as favorite. The catch rate is the share of customers who have the shop as favorite even if it is not the closest.

More formally, a shop $s$ is characterized by two customer sets. The first set is the set of customers that have $s$ as their closest shop, $C_{s}$. The second set is the set of customers that have $s$ as their favorite shop, $F_{s}$. The retention rate of $s, R(s)$, is the share of customers that have $s$ both as favorite and closest on the total number of closest customers, or:

$$
R(s)=\frac{\left|C_{s} \cap F_{s}\right|}{\left|C_{s}\right|}
$$

The catch rate of shop $s, S(s)$, is defined as the share of customers that have $s$ as favorite even if $s$ is not their closest shop, or:

$$
S(s)=\frac{\left|F_{s} \backslash C_{s}\right|}{\left|C . \backslash C_{s}\right|},
$$

where $C$. represents the set of all customers and $\backslash$ indicates the set difference operator.

\section{Results}

\subsection{Null hypothesis}

Before moving to the main results of the paper, we have to address one important concern. In the following sections we are going to show that product sophistication plays a significant role in the decision-making process of customers. However, it might be the case that the real factor influencing customers is the shop size. The null hypothesis is that larger shops have the more sophisticated products, therefore it is impossible to disentangle the sophistication effect from the shop size effect.

To disprove the null hypothesis we create a linear model. The model aims at explaining a shop's retention rate at increasing distances. Then, we characterize the shop's size using three different measures. The first measure is the total volume of its sales, i.e. the number of items that have been purchased in the shop. A larger shop generates high volumes of sales. The second measure is the shop's variety or assortment, i.e. the number of different products that can be purchased in the shop. Larger shops have a larger assortment of products. The last measure is the shop's sophistication. The shop's sophistication can be viewed as the average sophistication of the products sold at the shop, in the same way as the country sophistication is the average sophistication of the products it exports [7]. 
Table 1 Explaining retention with shop distance and size

\begin{tabular}{lllll}
\hline \multicolumn{4}{l}{ Dependent variable: $\boldsymbol{R}(\mathbf{s})$} & \\
\cline { 2 - 5 } & $\mathbf{( 1 )}$ & $\mathbf{( 2 )}$ & $\mathbf{( 3 )}$ & $\mathbf{( 4 )}$ \\
\hline Distance & $-0.026^{* * *}$ & $-0.026^{* * *}$ & $-0.026^{* * *}$ & $-0.026^{* * *}$ \\
Sophistication & $(0.001)$ & $(0.001)$ & $(0.001)$ & $(0.001)$ \\
Volume & & $0.110^{* * *}$ & $0.088^{* * *}$ & $0.085^{* * *}$ \\
& & $(0.004)$ & $(0.007)$ & $(0.020)$ \\
Variety & & $0.024^{* * *}$ & $0.022^{*}$ \\
& & & $(0.007)$ & $(0.012)$ \\
Constant & & & 0.006 \\
& & & & $(0.028)$ \\
Observations & $0.482^{* * *}$ & $0.444^{* * *}$ & $0.432^{* * *}$ & $0.432^{* * *}$ \\
$\mathrm{R}^{2}$ & $(0.013)$ & $(0.011)$ & $(0.012)$ & $(0.012)$ \\
Adjusted $\mathbf{R}^{2}$ & 2,393 & 2,393 & 2,393 & 2,393 \\
Residual Std. Error & 0.152 & 0.364 & 0.367 & 0.367 \\
F Statistic & 0.152 & 0.363 & 0.367 & 0.366 \\
\hline
\end{tabular}

$*_{p}<0.1 ; *^{*} p<0.05 ; * * * p<0.01$. Retention rate goes from 0 to 1 . Distance is calculated in minutes. The three measures of size (sophistication, volume and variety) are normalized with average 0 and standard deviation 1.

The null hypothesis states that the largest shops in terms of variety and/or volume will retain more customers, and that there is no variance left to explain for the shop's sophistication. In other words, customers just shop preferentially in larger and more variegated shops. However, our theory gives more importance to complex factors such as the shop's sophistication. We test a series of models that gradually introduce these factors into explaining the retention rate. All variables except distance have been normalized, fixing their average to 0 and their standard deviation to 1 , so that they are comparable even if distributed on different scales. Table 1 reports the results of our linear model.

First, we examine the effect of distance, calculated in number of minutes. As expected, the further a shop is, the lower the retention rate. Since $R(s)$ is computed as a share taking values from 0 to 1 , we can say that for each additional minute it takes to reach a shop, we lose two percentage points in the retention rate. If at 4 minutes $R(s)$ equals $75 \%$, at 8 minutes it is expected to drop to $67 \%$. The shop's sophistication plays a significant role: an increase of one standard deviation in sophistication increases the retention rate by 11 percentage points. Disproving the null model, sophistication persists in being significant even accounting for the shop's volume and variety. In particular, variety is not significant because it is already contained in the sophistication measure, which in turns corrects some of variety's issues. ${ }^{\mathrm{c}}$ Not only sophistication is significant, but its effect size also dominates the others.

With this test we disproved the proposed null hypothesis. Even if volume plays a role in determining a shop's retention rate, sophistication is the main driving factor. Shop sophistication is also a suitable way to interpret the results that will follow, as it sorts different shop types better than the other two variables. For instance, there is only one 'Super' shop with higher sophistication than an 'Iper', but four 'Super' shops with higher variety and the number of 'Iper' shops with lower volume than at least one 'Super' shop are four as well. These are significant figures, as there are only nine 'Iper' shops in the data. So sophistication captures the 'Iper,' 'Super', 'Gestin' shop division better than diversity and volume. 


\subsection{Retention and catch rates facts}

We now turn to describing the retention and catch rates for the different shop types. In all the following figures we always report on the $x$ axis the progressive distance of the shop from the customer and on the $y$ axis either the retention or the catch rate. Both $R(s)$ and $S(s)$ are aggregated per shop type. In practice, this means that we collapse all 'Iper' $s$ into the single entity 'Iper' and the same holds for 'Super' and 'Gestin'.

Figure 1 depicts the retention rates for different shop types at progressive spatial (left) and temporal distances (right). Note that the retention power is supposed to be high, as we assume the null hypothesis that the customer should go to the closest shop, choosing a different one only in case of distance ties. Instead, there is a strong difference between the retention power of different types of shops. Larger shops with more sophisticated products ('Iper') have the expected attraction power (around 60\% if they are very close, around 40\% when farther). Smaller shops ('Super') span from $40 \%$ to $20 \%$ on the same scales. Smallest shops ('Gestin') never retain $20 \%$ of the closest customers even if they are literally across the street.

With Figure 2, we report the catch rates for different shop types, again at progressive distances (spatial on the left, temporal on the right). Note that in the catch rate we are focusing only on customers that have a different shop type as the closest to their home.
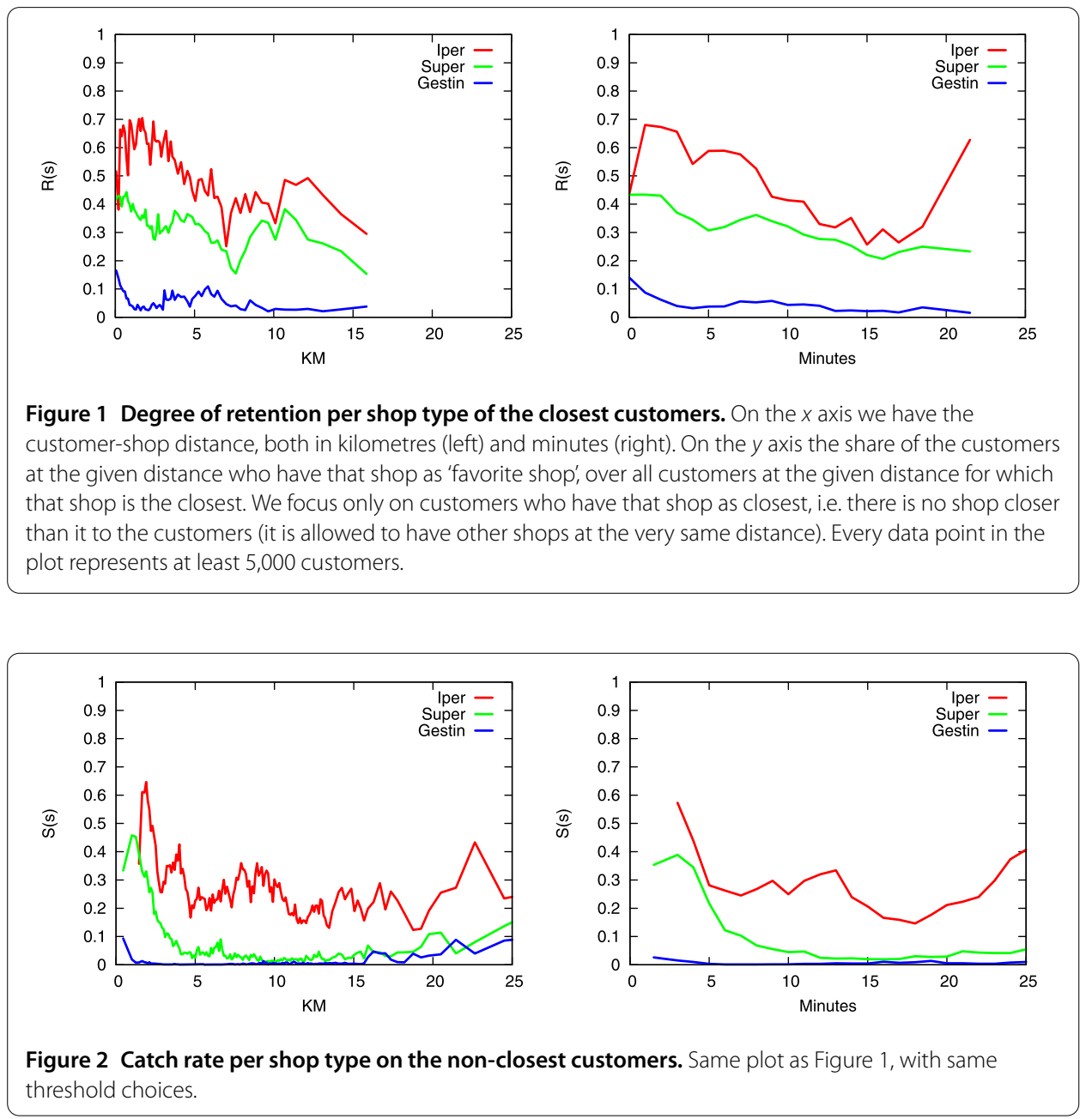
Table 2 Catch rates by shop type

\begin{tabular}{lllrl}
\hline \multirow{4}{*}{ Closest } & \multicolumn{3}{l}{ Favorite } & \\
\cline { 3 - 5 } & & Iper & Super & Gestin \\
\hline Minutes & Iper & $24.21 \%$ & $4.06 \%$ & $1.66 \%$ \\
& Super & $20.94 \%$ & $9.05 \%$ & $0.50 \%$ \\
& Gestin & $40.99 \%$ & $29.41 \%$ & $5.32 \%$ \\
KM & Iper & $24.98 \%$ & $3.13 \%$ & $1.72 \%$ \\
& Super & $24.03 \%$ & $8.09 \%$ & $0.67 \%$ \\
& Gestin & $44.59 \%$ & $33.52 \%$ & $6.08 \%$ \\
\hline
\end{tabular}

The table counts how many times a customer has as a favorite a shop that is not the closest to her.

The plot describes, for each shop type, the rate of customers attracted that should have chosen to go to a different shop, because closest. Peak catch rates are very different for the different shop types, from 'Iper' to 'Super' to 'Gestin' they respectively stop at 60$65 \%, 40-45 \%$ and 3-10\%. Asymptotic behavior is different only for the largest 'Iper' shops, resting at around 25-30\%. 'Super' and 'Gestin' do not show significant difference, resting both around $5 \%$ and $1 \%$ respectively. The conclusion from Figures 1 and 2 seems to be that the shop type has a large influence in the customer movement choice. Larger shops retain their closest customer base easily and they can attract significant portions of the customer bases of smaller shops, even at large distances.

In Table 2, we aggregate the information of the catch rates per shop type presented in Figure 2. In this case, we add the information about which shop type was the alternative for the customer, i.e. the closest one from which the favorite shop is catching the customer. Table 2 reports that, for instance, in $20.94 \%$ of the cases a customer who had as closest shop (in minutes) a 'Super' chose as her favorite shop a 'Iper'. In $40.99 \%$ of the cases, customers who had as closest (in minutes) a 'Gestin' chose as favorite a 'Iper. The interpretation of the data is that not only the attractive power is proportional to shop's sophistication (as seen in Figure 2), but also this attractive power is more effective the less sophisticated the alternative closest shop is.

\subsection{Product-dependent rates}

So far we have seen that the shop type plays a significant role in determining whether a customer will choose her closest shop as favorite or not. The result is not surprising: larger shops have greater attractive power. In this section, we present some facts proposing a possible motivation. We propose that customers decide to travel farther to larger shops because these shops can offer a larger assortment of more sophisticated products. This is an explanation based on the characteristics of the products that satisfy the needs of the customers, rather than based on other factors. We explore three main product characteristics: price, quantity needed and sophistication.

Figure 3 depicts the effect of price on the retention and catch rates. In the $y$ axis, we consider the ratio of high on low price product-seeking customers. A customer is high price seeking set if, in a given shop, she buys mostly products in the high price class $\left(\Pi_{p}=1\right)$. She is low price seeking if most of her purchased products in a given shop are from the low price class $\left(\Pi_{p}=0\right)$. A point on 1 in the $y$ axis means that customers at a given distance from their favorite shop ( $x$ axis) are evenly divided between both classes when buying items there. A point on 1.25 means that the set of high price seeking customers at a 


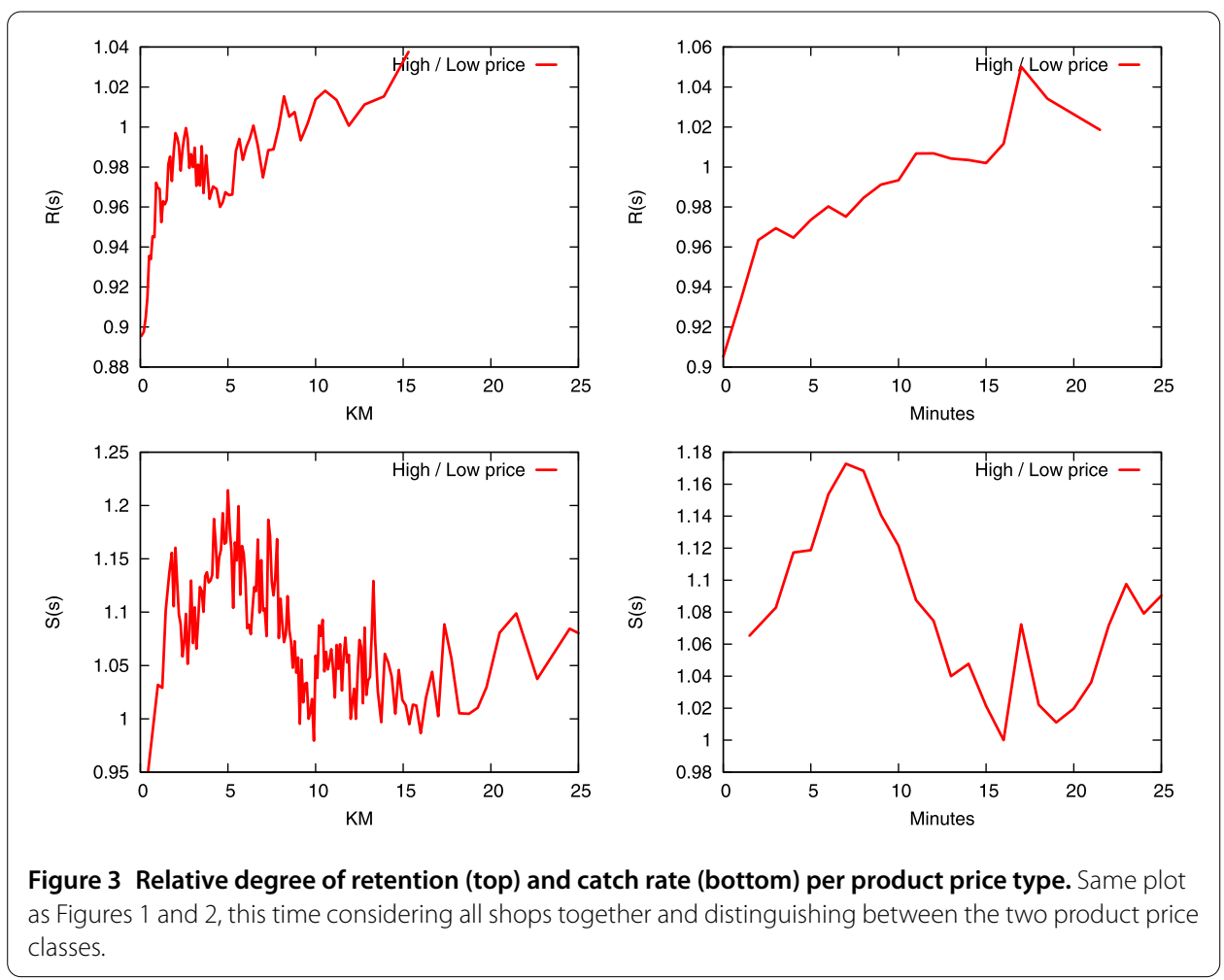

Table 3 Catch rates by shop type for high and low price products

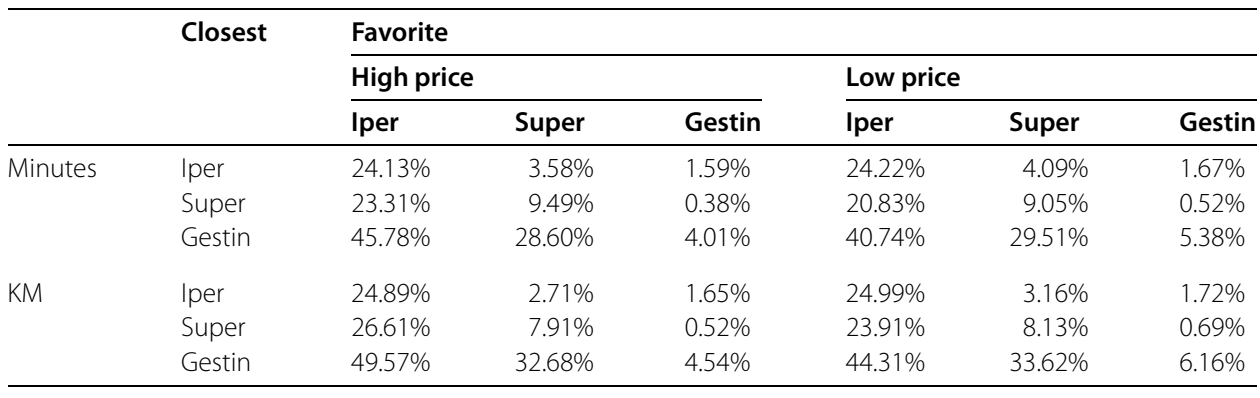

Same as Table 2, but focusing on high and low price products.

given distance from their favorite shop is $25 \%$ larger than the set of low price seeking customers. This interpretation applies to all figures in this section, substituting $\Pi_{p}$ with $Q_{p}$ and $S_{p}$ where appropriate.

Figure 3(top) shows that a nearby shop has $5-10 \%$ higher likelihood to be the favorite shop of a customer for low price products. A far away shop has $4 \%$ higher likelihood to be the favorite shop of a customer for high price products. Figure 3(bottom), focuses on the catch rate: if the shop is not the closest, it is more likely to catch customers from closest shops in high price products. This likelihood is around $15 \%$ higher if not too far, and it goes down to $3 \%$ higher for faraway shops. As a conclusion, we say that product price seems to play some role in the choice of the distance to be traveled. Customers are slightly more likely to travel more if they have to buy more expensive products.

In Table 3 we make the same operation we made for Table 2: we report the catch rate information depicted in Figure 3(bottom), considering also which shop type lost its cus- 


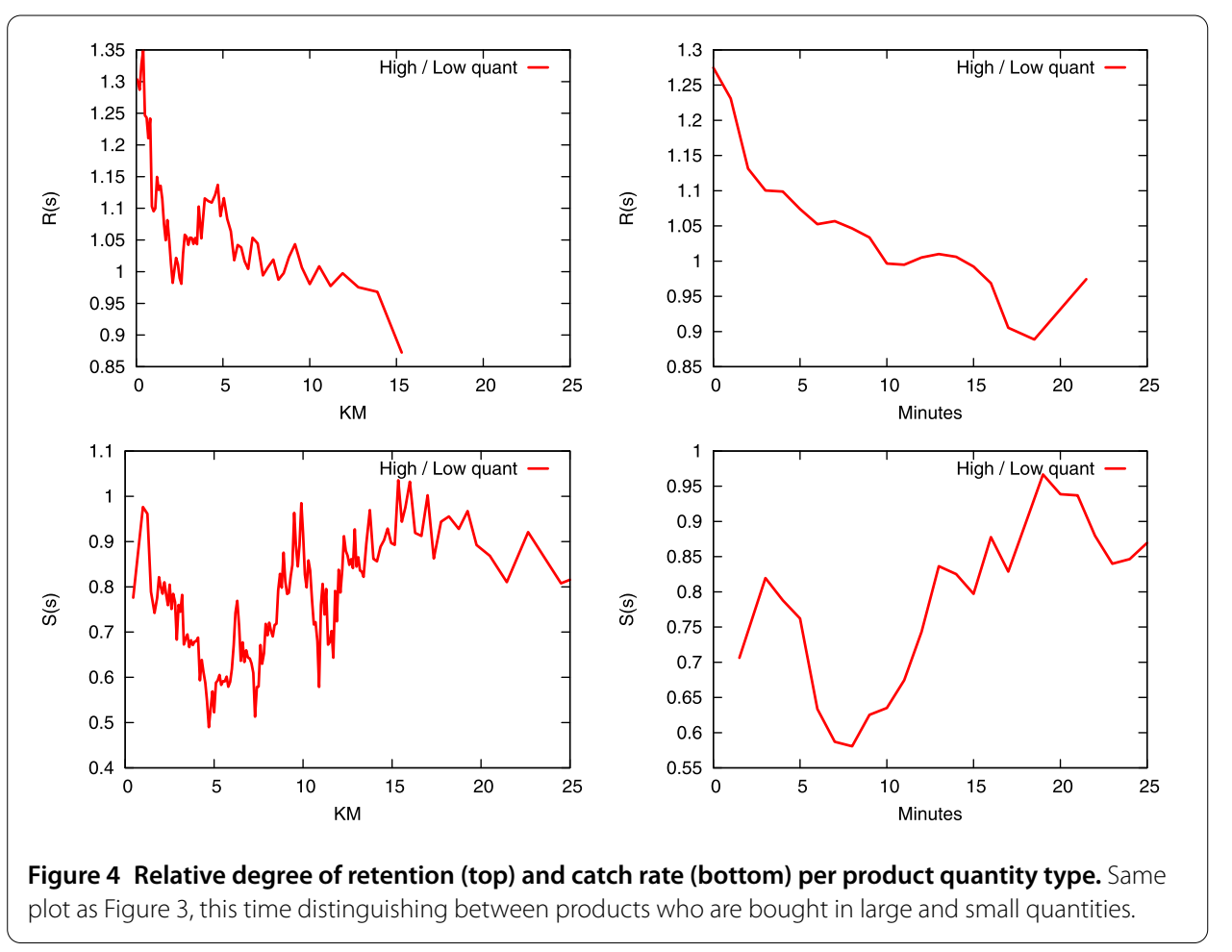

tomer. The catch rate for high price products for 'Iper' shops is higher, while for 'Super' and 'Gestin' is lower. The opposite holds for low price products. We can confirm that price plays a role when deciding to have a favorite shop.

We now turn our attention to the quantity variable. From Figure 4(top), we see that a nearby shop has $20-30 \%$ higher likelihood to be the favorite shop of a customer for high quantity products. A far away shop has $10 \%$ higher likelihood to be the favorite shop of a customer for low quantity products. Figure 4(bottom) shows that if the shop is not the closest, it is more likely to catch customers from closest shops in low quantity products. This likelihood is around 50\% higher if not too far, and it goes down to 10\% higher for faraway shops. As a conclusion, we say that product quantity seems to play a significant role in the choice of the distance to be traveled. Both indicators are higher than the price effect discussed in Figure 3. Customers are more likely to travel more if they have to buy products they need in lower quantities.

We again reinforce this result by splitting the catch rates according to which shop type was the closest to the customer, in Table 4 . The catch rate for low quantity products for 'Iper' shops is higher, while for 'Super' and 'Gestin' is lower. The opposite holds for low quantity products. The differences are larger than the ones seen in Table 3. On this basis, we conclude that quantity of purchase seems to play a larger role than the unit price when deciding to have a favorite shop.

We finally consider the effect of product sophistication in Figure 5. Figure 5(top) shows that a nearby shop has 30-35\% higher likelihood to be the favorite shop of a customer for non sophisticated products. A far away shop has 10\% higher likelihood to be the favorite shop of a customer for sophisticated products. As for catching rates, Figure 5(bottom) shows that, if the shop is not the closest, it is more likely to catch customers from closest shops in sophisticated products. This likelihood is around 55\% higher if not too far, and it 
Table 4 Catch rates by shop type for high and low quantity products

\begin{tabular}{|c|c|c|c|c|c|c|c|}
\hline & \multirow[t]{3}{*}{ Closest } & \multicolumn{6}{|c|}{ Favorite } \\
\hline & & \multicolumn{3}{|c|}{ High quantity } & \multicolumn{3}{|c|}{ Low quantity } \\
\hline & & Iper & Super & Gestin & Iper & Super & Gestin \\
\hline \multirow[t]{3}{*}{ Minutes } & Iper & $24.21 \%$ & $4.06 \%$ & $1.66 \%$ & $24.39 \%$ & $3.39 \%$ & $1.51 \%$ \\
\hline & Super & $20.90 \%$ & $9.04 \%$ & $0.51 \%$ & $30.39 \%$ & $12.79 \%$ & $0.54 \%$ \\
\hline & Gestin & $40.91 \%$ & $29.45 \%$ & $5.34 \%$ & $53.82 \%$ & $26.97 \%$ & $2.57 \%$ \\
\hline \multirow[t]{3}{*}{ KM } & Iper & $24.98 \%$ & $3.14 \%$ & $1.72 \%$ & $25.16 \%$ & $2.53 \%$ & $1.57 \%$ \\
\hline & Super & $23.99 \%$ & $8.10 \%$ & $0.68 \%$ & $34.02 \%$ & $10.13 \%$ & $0.66 \%$ \\
\hline & Gestin & $44.51 \%$ & $33.55 \%$ & $6.10 \%$ & $57.31 \%$ & $30.59 \%$ & $2.89 \%$ \\
\hline
\end{tabular}

Same as Table 3, but focusing on high and low quantity products, rather than price.

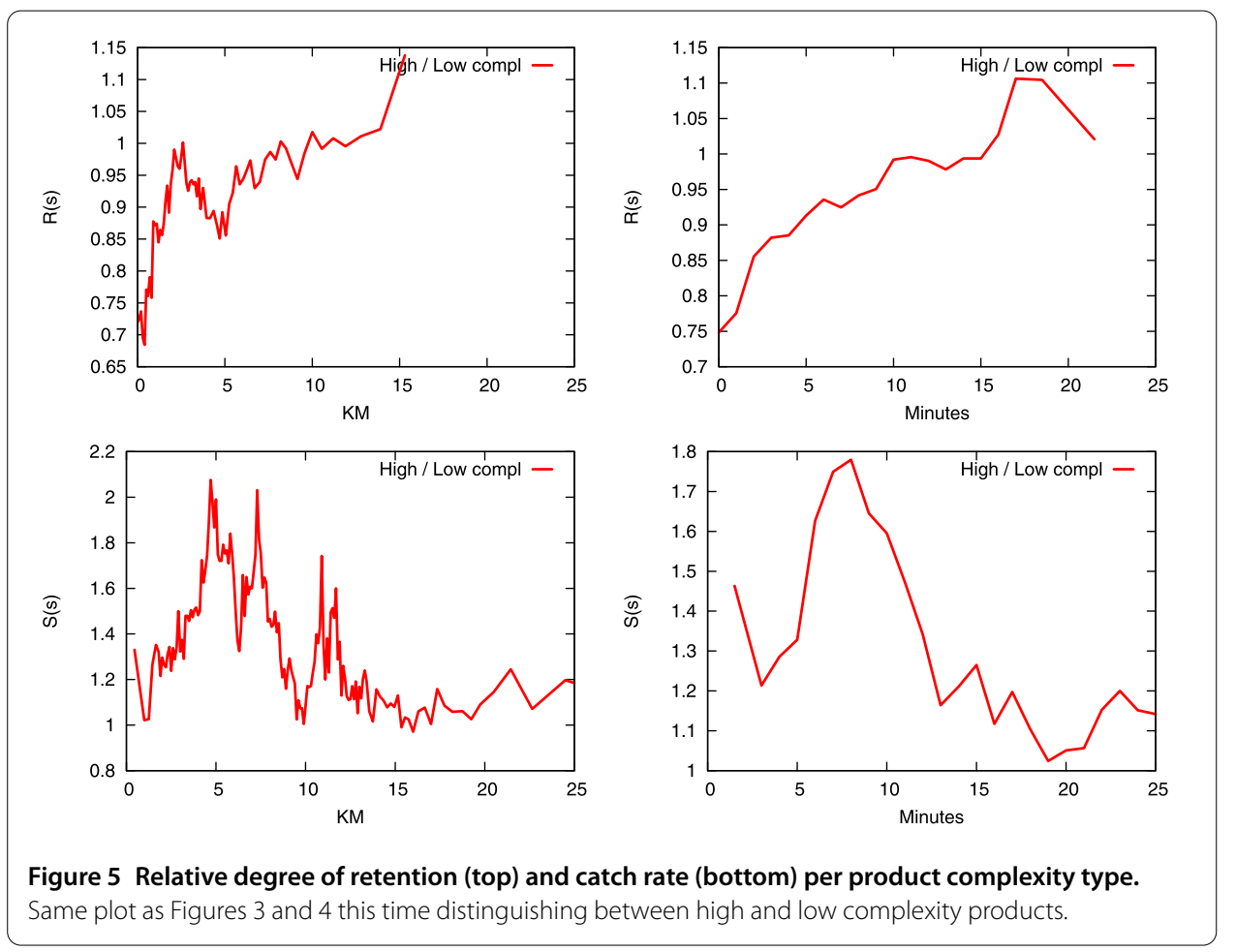

goes down to $10 \%$ for faraway shops. As a conclusion, we say that product sophistication seems to play a significant role in the choice of the distance to be traveled. The indicators are comparable to the ones of product quantity seen in Figure 4, only marginally higher. Customers are more likely to travel more if they have to buy sophisticated products.

Table 5 reports the same rates by splitting them according to the closest shop type. The catch rate for high complexity products for 'Iper' shops is higher, while for 'Super' and 'Gestin' is lower. The opposite holds for low complexity products. The differences are larger than the ones seen in Tables 3 and 4. We conclude that the complexity of a product seems to play the largest role, larger than both price and quantity of purchase, when deciding to have a favorite shop.

We conclude this analysis by looking at the customer's behavior when visiting her favorite shop as opposed to visiting her closest shop. We average the price, quantities and sophistication of the products she purchases at these two shops. We only report a cus- 
Table 5 Catch rates by shop type for high and low complexity products

\begin{tabular}{|c|c|c|c|c|c|c|c|}
\hline & Closest & Favorite & & & & & \\
\hline & & High co & xity & & Low cor & xity & \\
\hline & & Iper & Super & Gestin & Iper & Super & Gestin \\
\hline Minutes & $\begin{array}{l}\text { Iper } \\
\text { Super } \\
\text { Gestin }\end{array}$ & $\begin{array}{l}24.27 \% \\
31.22 \% \\
55.93 \%\end{array}$ & $\begin{array}{r}2.78 \% \\
12.43 \% \\
26.19 \%\end{array}$ & $\begin{array}{l}1.48 \% \\
0.42 \% \\
2.02 \%\end{array}$ & $\begin{array}{l}24.21 \% \\
20.67 \% \\
40.45 \%\end{array}$ & $\begin{array}{r}4.13 \% \\
9.06 \% \\
29.71 \%\end{array}$ & $\begin{array}{l}1.67 \% \\
0.51 \% \\
5.41 \%\end{array}$ \\
\hline KM & $\begin{array}{l}\text { Iper } \\
\text { Super } \\
\text { Gestin }\end{array}$ & $\begin{array}{l}25.02 \% \\
35.08 \% \\
59.55 \%\end{array}$ & $\begin{array}{r}2.07 \% \\
9.64 \% \\
29.91 \%\end{array}$ & $\begin{array}{l}1.54 \% \\
0.54 \% \\
2.27 \%\end{array}$ & $\begin{array}{l}24.99 \% \\
23.73 \% \\
44.02 \%\end{array}$ & $\begin{array}{r}3.19 \% \\
8.14 \% \\
33.84 \%\end{array}$ & $\begin{array}{l}1.72 \% \\
0.68 \% \\
6.18 \%\end{array}$ \\
\hline
\end{tabular}

Same as Tables 3 and 4, but focusing on high and low complexity products.
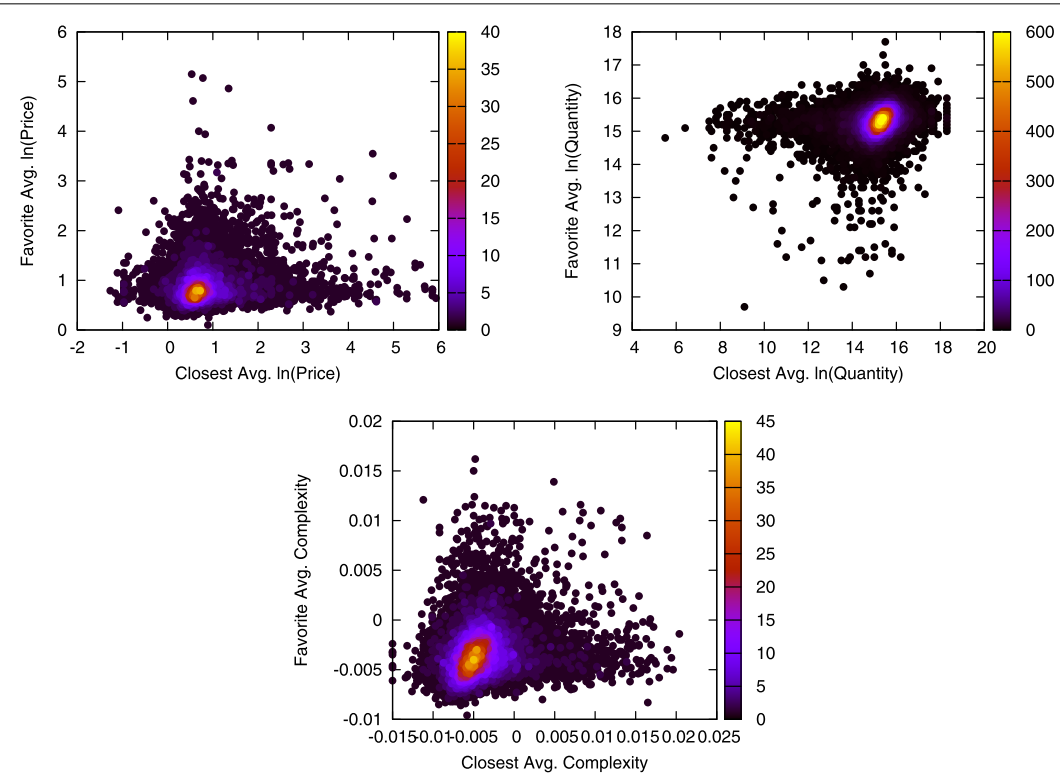

Figure 6 Relationship between what customers buy in their closest shop and in their favorite shop, when different. In all plots, each dot is a customer. The $x$ axis represents the average product characteristics of the products she bought in the closest shop. In the $y$ axis, we have the same product characteristics of her purchases, this time calculated over the products bought in her favorite shop, when this is not the closest. Point color is proportional to the number of customers sharing the same values. The products characteristics are the product price (top left), the product quantity (top right) and the product complexity (bottom). Product price and quantity are in natural logarithm.

tomer if the closest and the favorite shops are different. Figure 6 depicts the resulting distributions: price on the left, quantity in the middle and sophistication on the right. The plots can be summarized as follows:

- Most customers tend to behave in the same way in their closest and in their favorite shops. The high concentration of data points corresponds to equivalent prices, quantities and sophistications on both axes;

- The customers that behave in the same way in their closest and in their favorite shops tend to have low sophistication. The average sophistication of these customers is between -0.01 and 0 . The sophistication is normalized with average of 0 , so these customers are the ones that are below sophistication average; 
- There is a pervasive L-shaped pattern. This means that the sophisticated customers (and the ones that spend more on average per item) tend to have two wildly different behaviors in the closest and favorite shops. They tend to buy the expensive and sophisticated products only in one of the two shops and use the other one for bulk, not sophisticated purchases.

Our conclusion is that the customers who actually have different behaviors in the closest and in the favorite shop are the 'extreme' ones, the one buying products at high sophistication (low quantities, high prices). When a customer instead has a low sophistication (high quantity, low prices), her behavior does not change between closest and favorite shops.

\subsection{Shop survival}

We conclude by looking at the relationship between the retention and catch rates of shops, and their success. As reported in the data section, we know whether a shop was closed during our observation period. We then aggregate the data by splitting shops not only according to their type ('Iper,' 'Super' and 'Gestin'), but also according to their status (Closing 'Iper', if the 'Iper' was closed during our observation period, Non Closing 'Iper' if it was not, and so on). We end up with six shop classes, that we analyze as we did in the previous sections.

Figure 7 reports the degrees of retention and of catch rate for the six classes. Instead of reporting all of them directly, we just calculate the rate ratios of Non Closing (NC) versus Closing $(\mathrm{C})$ for the same shop type. We can see that different shop types have very different behaviors.

In Figure 7(top) we can see that for 'Super' the degree of retention of surviving shops is around 20 times higher, for 'Iper' is around 2 times higher, while for 'Gestin' it appears that the degree of retention of closed shops was actually higher for faraway shops.
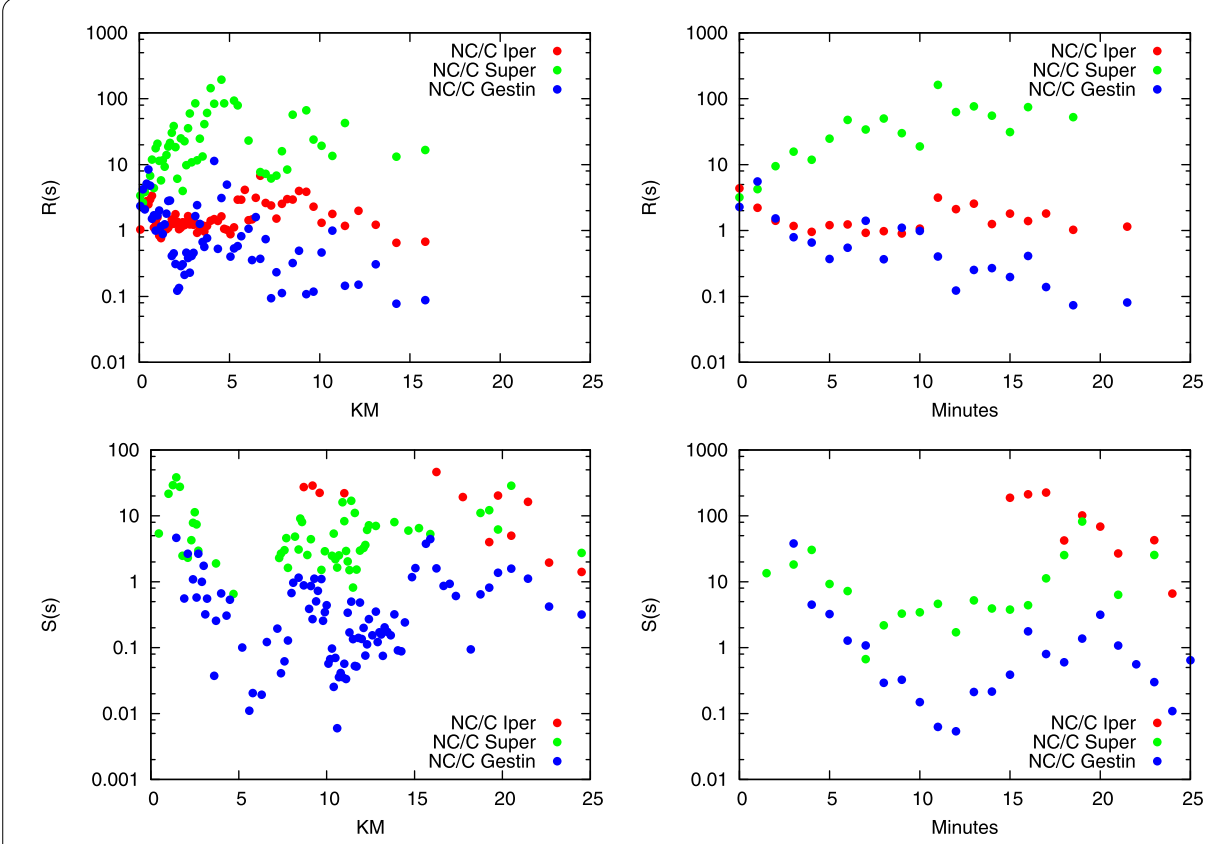

Figure 7 Degree of retention (top) and catch rate (bottom) per shop type, ratio between shops still open and shops that closed. 
Figure 7(bottom) shows that catch rates are subject to higher variation. For 'Iper' shops the catch rate of surviving shop was much higher than for 'Super' shops. 'Gestin' shops have higher variation, but it averages around 1 (no difference).

As a conclusion, it looks like 'Super' shops get closed if they have a lower degree of retention on their closest customers, while 'Iper' shops get closed if they have lower catch rates on non-closest customers. 'Gestin' shops are harder to describe.

\section{Discussion}

\subsection{Results in context with previous literature}

This work is part of the literature effort of creating models of human mobility. In particular, we focus on the mobility of customers in a market environment. How do customers decide when and where to shop? What are the most important factors influencing these choices? This research literature is very prolific and it is touched from a number of approaches. We depart from classical marketing analysis [9-11] and the classic data mining community [12-14], to embrace the more systemic view, putting together the social physics approach with the classical Central Place Theory developed in the 1930s [4]. We do so by collecting a large amount of data about the overall behavior of the retail population as a whole system and empirically validate the CPT prediction. Namely, we focus on the idea that shops providing a higher order of goods and services, which have a larger range, cause people to be willing to travel longer distances to visit them.

CPT has a long history, not exempt from criticism [6]. In this paper, we show that CPT's central idea holds in retail when tested against real world data, which mandate to drop some of the most troubling assumptions. For instance, the geographical space investigated is not boundless, there is no perfect competition, customers do not have the same needs nor the same purchasing power. In fact, we have shown that it is exactly the behavioral difference of customers, the different sophistication of their needs, that drives their willingness to travel. Our work is in line with more recent formulations of CPT, which discuss more sophisticated network dynamics $[5,15]$ and a relaxation of CPT with overlapping regions of influence [16]. We are also not the first to test CPT in the retail scenario [17]. However, this previous literature focuses on a more coarse view of the retail system, without investigating the actual micro behavior of each individual customer, which we can and do observe in our work.

Focusing on social physics applied to retail, a classic result shows the high degree of predictability in customer behavior over a long term temporal span [1]. In our previous work, we proposed the sophistication explanation: customers travel more to satisfy their most sophisticated needs [2]. This result shows that customers are self-organizing parts of a complex system [3]. There have been attempts on improving the resolution of the mobility prediction on shorter time scales [18]. Here we improve over our previous work by using a more realistic measure of customer-shop distance, and investigating deeper implications of shop and product types on customer mobility.

Our data lacks a social dimension, meaning that we do not know which customers know which other customers. This is a severe limitation to our study, because there are multiple works that are able to connect human mobility with social connection. Classic results show that if people visit the same places it is possible to predict that they have a higher likelihood to become friends and vice versa [19-22]. This literature has important applications. One worth noticing is in the economic development for socially segregated societies in developing countries [23]. 
Works like the one presented in this paper and the ones discussed in this section are affected by a number of methodological and ethic issues. As for the methodology, one challenge is the necessity of controlling for place distributions. Cities are not built in a random way and this distribution of interesting hot spots might influence the results [24]. On the ethics side, we note that the predictability of human movement always carries an identification hazard, as it has been shown multiple times in literature, for example in [25]. Work has been done to create location-based apps that can ensure the privacy of its users [26].

We conclude the literature review by reporting that the human mobility prediction works like the one presented here have a number of different applications. One of the classical application is in disease prevention. To understand how people move, both at a macro and at a micro scale, would empower us to prevent disease outbreaks, or at least to ensure that they can be effectively confined in restricted areas [27-29]. There are also market applications to improve the way in which citizens are able to use the public transportation infrastructure. A very novel and fast evolving research track studies the dynamics of car sharing and on demand taxi services [30, 31].

\subsection{Strength and limitations of this study}

In this study, we improve over previous works on four factors:

- we frame our results in a more coherent theoretical framework, namely the one created with the idea of the Central Place Theory,

- we use a more realistic distance measure to evaluate customer mobility,

- we improve the description precision of the customer mobility decision making process by considering both product and shop characteristics,

- and we provide a description of the logic with which different shop types are pushed out of business.

These are the main strengths of the paper, because they increase the precision and descriptive ability of researchers and market analysts when dealing with the problem of describing human mobility in a market context, and they connect this ability with the Central Place theoretical foundation.

Our study is not exempt from some limitations. The main limitations we see are the following two: the disentanglement of intrinsic shop characteristics and the uncertainty of the actual customer location. We now briefly discuss both.

In the paper we show different dynamics for different shop types. Larger shops ('Iper') have higher retention and catch rates, especially against the smallest shops ('Gestin'). The hypothesis still to be tested is if this effect has anything to do with the shops' intrinsic power (shops are larger, thus fulfill more needs), or if there are external explanations (larger shops have better infrastructure). We need to integrate our data sources with other information about how people access the shops: do the shops have larger parking lot? Are they better served by public transportation? Are the customers visiting them by car or by foot? These and other questions need to be answered to have a fully controlled experiment on customer mobility. Our results partially address these concerns. Given that we find strong product-dependent variables, it means that the object of the purchase is playing an effect on customer's mobility. If infrastructure-type variables would be the only important factor, we would not see the rates we described in this paper.

Moving to customer's characteristics, we have reported that for each customer we have the home address. We do not have the customer's work location and it is possible that 
customers will go to a retail shop after their work day. This would contaminate the results, because the starting location of the retail trip would be different from the one we think it is. However, the noise introduction is minimal. What changes is the origin of the retail trip, but the destination is bounded to always be the same. In any case, the end point of a retail visit is always the customer's home location.

\subsection{Conclusion}

In this paper we provided further insights about the mobility of customers in a market system. We made use of actual routes from the customers' home locations to the shop they visit, along with the actual time it takes to use these routes. On top of this data, we are able to identify, for each customer, what is their closest shop and what is their favorite one, i.e. the one from which they buy most of the products they need. When the two are different, we showed that different shop types have different rates of retaining their closest customers and of attracting customers that are closer to a different shop. We show evidences that these differences in attraction and retention rates are partially explained by the characteristics of the products customers buy: more expensive and more sophisticated products are the ones for which customers travel the most. This is an empirical validation of the more modern formulations of the Central Place Theory, where central places are more attractive depending on the variety of needs they can satisfy. We showed that different shop types have a different relationship with their market audience: larger shops are unsuccessful if they cannot attract customers from other nearby shops, while medium size shops are unsuccessful if they cannot retain their nearby customers.

Our work opens the way to several future developments. First, we need to better establish the relationship between shop size and the quality of the infrastructure surrounding the shop. Larger shops might have better parking lots, being more accessible even if farther away and so on. By controlling for these factors, we can actually evaluate the net effect of product price and sophistication on customer's mobility decisions. Second, we can move towards the data mining community and use these features in a predictive framework that, given a customer and a product, will be able to suggest the amount of time the customer is willing to invest to obtain the product. There are a number of marketing applications that could benefit both customers and retailers. Finally, we can explore what are the privacy implications of such systems. These applications will have to ensure that the personal information of the customers is never jeopardized.

Competing interests

The authors declare that they have no competing interests.

Authors' contributions

DP and MC performed research, prepared figures, carried out empirical analysis and wrote the manuscript. All authors designed research and reviewed the manuscript.

Author details

${ }^{1}$ CID, Harvard University, 79 JFK St, Cambridge, USA. ${ }^{2}$ IMT, P.za San Ponziano 6, Lucca, Italy. ${ }^{3}$ ISTI, CNR, Via G. Moruzzi, 1 , Pisa, Italy. 


\section{Endnotes}

a https://developers.google.com/maps/documentation/directions/.

b At least more reasonable than straight line distance. The few helicopter-owning customers should not skew the results too much.

c In fact, adding a non-sophisticated product like water increases variety but decreases complexity, and arguably no customer would decide to travel more because a shop sells also water.

\section{Received: 14 April 2015 Accepted: 28 September 2015 Published online: 09 October 2015}

\section{References}

1. Krumme C, Llorente A, Cebrian M, Moro E et al (2013) The predictability of consumer visitation patterns. Sci Rep 3:1645

2. Pennacchioli D, Coscia M, Rinzivillo S, Pedreschi D, Giannotti $F$ (2013) Explaining the product range effect in purchase data. In: 2013 IEEE international conference on big data, pp 648-656

3. Pennacchioli D, Coscia M, Rinzivillo S, Giannotti F, Pedreschi D (2014) The retail market as a complex system. EPJ Data Sci 3(1):33

4. Berry BJ, Garrison WL (1958) Recent developments of central place theory. Pap Reg Sci 4(1):107-120

5. Meijers E (2007) From central place to network model: theory and evidence of a paradigm change. Tijdschr Econ Soc Geogr 98(2):245-259

6. Parr JB, Denike KG (1970) Theoretical problems in central place analysis. Econ Geogr 46(4):568-586

7. Hausmann R, Hidalgo C, Bustos S, Coscia M, Chung S, Jimenez J, Simoes A, Yildirim M (2011) In: The atlas of economic complexity. Puritan Press, Hollis

8. Caldarelli G, Cristelli M, Gabrielli A, Pietronero L, Scala A, Tacchella A (2011) Ranking and clustering countries and their products; a network analysis. arXiv: 1108.2590

9. Foxall GR (2005) Understanding consumer choice. Palgrave Macmillan, Basingstoke

10. Shen Z-JM, Su X (2007) Customer behavior modeling in revenue management and auctions: a review and new research opportunities. Prod Oper Manag 16(6):713-728. doi:10.1111/j.1937-5956.2007.tb00291.x

11. Underhill P (2000) Why we buy: the science of shopping. Simon \& Schuster, New York. http://www.amazon.com/exec/obidos/redirect?tag=citeulike07-20\&path=ASIN/0684849143

12. Agrawal R, Imielinski T, Swami AN (1993) Mining association rules between sets of items in large databases. In: SIGMOD international conference, pp 207-216

13. Kocakoç ID, Erdem S (2010) Business intelligence applications in retail business: OLAP, data mining \& reporting services. J Inf Knowl Manag 9(2):171-181

14. $\mathrm{Li} \mathrm{H}$ (2005) Applications of data warehousing and data mining in the retail industry. In: Proceedings of ICSSSM'05. 2005 international conference on services systems and services management, vol 2, pp 1047-1050

15. Taylor PJ, Hoyler M, Verbruggen R (2010) External urban relational process: introducing central flow theory to complement central place theory. Urban Stud 47(13):2803-2818

16. South R, Boots B (1999) Relaxing the nearest centre assumption in central place theory. Pap Reg Sci 78(2):157-177

17. Dennis C, Marsland D, Cockett T (2002) Central place practice: shopping centre attractiveness measures, hinterland boundaries and the UK retail hierarchy. J Retail Consum Serv 9(4):185-199

18. Schneider CM, Belik V, Couronné T, Smoreda Z, González MC (2013) Unravelling daily human mobility motifs. J R Soc Interface 10(84):20130246

19. Cho E, Myers SA, Leskovec J (2011) Friendship and mobility: user movement in location-based social networks. In: Proceedings of the 17th ACM SIGKDD international conference on knowledge discovery and data mining, pp 1082-1090

20. De Domenico M, Lima A, Musolesi M (2013) Interdependence and predictability of human mobility and social interactions. Pervasive Mob Comput 9(6):798-807

21. Miritello G, Lara R, Moro E (2013) Time allocation in social networks: correlation between social structure and human communication dynamics. In: Temporal networks. Springer, Berlin, pp 175-190

22. Toole JL, Herrera-Yaqüe C, Schneider CM, González MC (2015) Coupling human mobility and social ties. J R Soc Interface 12(105):20141128

23. Amini A, Kung K, Kang C, Sobolevsky S, Ratti C (2014) The impact of social segregation on human mobility in developing and industrialized regions. EPJ Data Sci 3(1):6

24. Noulas A, Scellato S, Lambiotte R, Pontil M, Mascolo C (2012) A tale of many cities: universal patterns in human urban mobility. PLOS ONE 7(5):37027

25. de Montjoye Y-A, Hidalgo CA, Verleysen M, Blondel VD (2013) Unique in the crowd: the privacy bounds of human mobility. Sci Rep 3:1376

26. Sweatt B, Paradesi S, Liccardi I, Kagal L, Pentlandz A (2014) Building privacy-preserving location-based apps. In: 2014 twelfth annual international conference on privacy, security and trust (PST), pp 27-30

27. Bajardi P, Poletto C, Ramasco JJ, Tizzoni M, Colizza V, Vespignani A (2011) Human mobility networks, travel restrictions, and the global spread of 2009 H1N1 pandemic. PLoS ONE 6(1):16591

28. Belik V, Geisel T, Brockmann D (2011) Natural human mobility patterns and spatial spread of infectious diseases. Phys Rev X 1(1):011001

29. Halloran ME, Vespignani A, Bharti N, Feldstein LR, Alexander K, Ferrari M, Shaman J, Drake JM, Porco T, Eisenberg J et al (2014) Ebola: mobility data. Science 346(6208):433

30. Shmueli E, Mazeh I, Radaelli L, Pentland AS, Altshuler Y (2015) Ride sharing: a network perspective. In: Social computing, behavioral-cultural modeling, and prediction. Springer, Berlin, pp 434-439

31. Santi P, Resta G, Szell M, Sobolevsky S, Strogatz SH, Ratti C (2014) Quantifying the benefits of vehicle pooling with shareability networks. Proc Natl Acad Sci USA 111(37):13290-13294 